\title{
Does transparency imply efficiency? The case of the European soccer betting market
}

\author{
Anastasios Oikonomidis ${ }^{1}$, Alistair C. Bruce ${ }^{2}$ and Johnnie E.V. Johnson ${ }^{1}$ \\ ${ }^{1}$ Southampton Business School, University of Southampton. \\ ${ }^{2}$ Nottingham University Business School, University of Nottingham.
}

\begin{abstract}
We discover mispricing in an apparently transparent market - the European soccer betting market. Efficiency differences between countries are accounted for by variations in league competitiveness. We conclude that barriers to efficiency (e.g., risk evaluation problems) may remain in transparent markets.
\end{abstract}

\subsection{Introduction}

The recent financial crisis has been attributed to many competing causes. Prominent amongst these are inappropriately high risk exposure by financial institutions and enhanced trading in increasingly complex financial assets, where reliable evaluation of fundamental asset risk is elusive and/or attended by significant transactions costs. The crisis has also prompted more fundamental questions regarding the allocative effectiveness of markets. For example, Paul Volcker, former Federal Reserve Chairman, claimed that "among the causes of the recent financial crisis was an unjustified faith in rational expectations [and] market efficiencies" (Volcker, 2011, p.1). This has led authorities in the US and Europe to initiate moves towards transparent markets that have "highly visible prices and volumes, broad market participation including retail agents, and elimination of counterparty risk through standardized margins" (Acharya et al., 2009, p.169).

We explore whether an expectation of efficiency in a financial market, which is untroubled by the stress factors identified above, is warranted or whether barriers to efficiency remain. To achieve this we investigate a market operating under ostensibly favourable circumstances. Specifically, we investigate the European soccer betting market, which deals in simple, commodity-type, state-contingent assets, where asset values are determined exclusively by the outcomes of soccer matches, with only three outcomes possible (home or away win, draw). The market is internet-based, suggesting relative freedom from transactions costs (Smith and Brynjolfsson, 2000). Unwarranted inflation of trader expectations is avoided by the daily stream of final market outcomes which invites a realistic view of returns prospects.

\subsection{Material and Methods}

\subsection{Testing for Inefficiency}


We analyse data from Gamebookers, a major internet bookmaker, relating to the European soccer betting market. Odds for each potential match outcome and result data are collected for 52,865 soccer matches across twenty two leagues in eleven European countries between 1999 and 2008.

Procedure 1 tests for weak form efficiency by examining whether expected profitability differs across odds values, both for individual leagues and in aggregate. It also explores whether prices (odds) exhibit favourite-longshot bias (FLB), the under/overestimation of the probability of favourites/longshots; a well-established manifestation of market inefficiency. Odds are segmented into twelve categories, and match outcome data are used to calculate average profit per category, assuming level staking on each betting opportunity. We then determine for each category the expected profit to a unit bet, allowing for 'overround' (percentage by which the sum of implicit probabilities for the three possible event outcomes exceeds one) and we compare the ratio of actual to expected returns across odds categories.

Procedure 2 employs a conditional logit (CL) regression, with the outcome of each game as the dependent variable and log of the odds-implied probability (Lodds) as the independent variable. The dependent variable takes value 1 for the event that occurred (e.g., draw) and 0 for those that did not occur. When the coefficient of Lodds is 1 there is no FLB; when it is significantly less/more than 1 the chances of favourites are over/under-estimated.

\subsection{Explaining Efficiency Differentials}

Following Vaughan Williams and Paton (1997), we explore the role of transactions costs (measured via the overround) in explaining observed inefficiency differentials. Procedure 3 examines the log-likelihoods of two CL models, both with the outcome of each game as the dependent variable and containing an interaction term as an independent variable: Lodds $\mathrm{X}$ level of transaction costs (to ensure this term varies across the three possible game outcomes). Model 1 includes Lodds as an additional independent variable; Model 2 includes Lodds multiplied by a dummy variable, which takes the value 1 if a league displays significant FLB (from results in Table 2) and 0 otherwise. Clearly, if differences in transactions costs can explain differential FLB between betting markets, there should be no difference in the information content of these two models.

We also consider whether differences in league competitiveness explain cross-league differentials in FLB. If odds-setters underestimate cross-league differences in competitiveness, less competitive leagues will exhibit greater FLB as favourites will be assigned odds which understate, to a greater degree, their true winning probability. We explore this via Procedures 4 and 5. In Procedure 4, we use mean absolute goal difference per game per season (meanAGD) in each league as a proxy for league competitiveness in that season. A league's competitiveness across the ten seasons (1999-2008) is then determined as the mean of these seasonal competitiveness values. We then explore the degree of correlation between a league's competitiveness and the FLB exhibited in that league, where the FLB is determined by the coefficient of Lodds in a conditional logit model estimated across all ten years of games for a given league, with the outcome of each game as the dependent variable. 
Procedure 5 ensures that the results relating to the relationship between competitiveness and efficiency are robust. We assess the competiveness of each league by the degree to which odds accurately account for each team's actual winning probability. This assumes that in highly competitive leagues, results are less predictable. Consequently, we employ the McFadden $\mathrm{R}^{2}$ statistic associated with each league's estimated CL function (Lodds as the sole independent variable), based on all games played across the ten seasons. This statistic serves as a proxy for a league's predictability and hence competitiveness. Correlation between this competitiveness statistic and FLB is assessed for each league.

\subsection{Results}

\subsection{Efficiency Characteristics}

Profitability variations across odds ranges are observed for the aggregate sample, indicating a degree of positive FLB, and therefore inefficiency, overall (Table 1). The results of estimating the CL model (Procedure 2) confirm the positive FLB, the majority of leagues displaying a significantly positive coefficient for Lodds (Table 2). However, the results indicate significant cross-league diversity, in terms of the magnitude and sign of FLB, an important result given the fundamental similarity of the markets.

Table 1: Mean profit and actual/expected returns across odds categories for betting markets associated with 52,865 soccer games across 22 European soccer leagues $(1999-2008)$.

\begin{tabular}{lll}
\hline $\begin{array}{l}\text { Decimal odds } \\
\text { category }\end{array}$ & $\begin{array}{l}\text { Mean profit } \\
\text { per bet }\end{array}$ & $\begin{array}{l}\text { Actual/expected } \\
\text { return }\end{array}$ \\
\hline$\leq 1.5$ & -0.034 & 1.085 \\
$>1.5, \leq 1.8$ & -0.072 & 1.043 \\
$>1.8, \leq 2.0$ & -0.069 & 1.046 \\
$>2.0, \leq 2.4$ & -0.081 & 1.033 \\
$>2.4, \leq 2.8$ & -0.111 & 0.999 \\
$>2.8, \leq 3.1$ & -0.118 & 0.991 \\
$>3.1, \leq 3.2$ & -0.134 & 0.973 \\
$>3.2, \leq 3.3$ & -0.108 & 1.002 \\
$>3.3, \leq 3.5$ & -0.112 & 0.998 \\
$>3.5, \leq 4.0$ & -0.161 & 0.943 \\
$>4.0, \leq 5.0$ & -0.157 & 0.947 \\
$>5.0$ & -0.28 & 0.809 \\
\hline
\end{tabular}

Table 2: Results of estimating a CL model with an index function made up of interaction terms between Lodds and binary variables which indicate the league in which the particular game is played (52,865 soccer games, 1999 - 2008).

\begin{tabular}{lll}
\hline $\begin{array}{l}\text { Interaction } \\
\text { terms }{ }^{1} \text { : binary } \\
\text { variable }\end{array}$ & Coefficient & z-value \\
identifying & & \\
league x Lodds & & \\
\hline Spain2 & & \\
England3 & 0.936 & $14.70^{* * *}$ \\
Scotland1 & 0.989 & $18.71^{* * *}$ \\
England1 & 0.999 & $12.12^{* * *}$ \\
England2 & 1.019 & $20.61^{* * *}$ \\
& 1.029 & $20.51^{* * *}$
\end{tabular}




\begin{tabular}{lcc} 
Spain1 & 1.044 & $20.95^{* * *}$ \\
Scotland2 & 1.044 & $12.20^{* * *}$ \\
Germany2 & 1.103 & $16.45^{* * *}$ \\
Germany1 & $1.117^{+}$ & $20.13^{* * *}$ \\
England Conf. & 1.125 & $13.52^{* * *}$ \\
France1 & $1.128^{+}$ & $19.10^{* * *}$ \\
Portugal1 & $1.136^{+}$ & $19.45^{* * *}$ \\
Turkey1 & $1.170^{+}$ & $20.66^{* * *}$ \\
England Prem. & $1.191^{+}$ & $24.78^{* * *}$ \\
Scotland Prem. & $1.194^{+}$ & $21.10^{* * *}$ \\
France2 & $1.204^{+}$ & $18.11^{* * *}$ \\
Belgium1 & $1.208^{+}$ & $22.58^{* * *}$ \\
Netherlands1 & $1.247^{+}$ & $24.66^{* * *}$ \\
Italy1 & $1.253^{+}$ & $24.27^{* * *}$ \\
Italy2 & $1.270^{+}$ & $21.06^{* * *}$ \\
Greece1 & $1.300^{+}$ & $22.30^{* * *}$ \\
Scotland3 & $1.330^{+}$ & $17.78^{* * *}$ \\
\hline Tr league N in that country x Lodds \\
ter than 1 with 95\% confidence \\
0.1\%
\end{tabular}

\subsection{Explaining Efficiency Differentials}

Table 3 details the results of Procedure 3. A likelihood ratio test confirms that the log-likelihood of Model 2 (which accounts for the efficiency of the betting market associated with the league in which the game is played) is significantly greater than the log-likelihood of the CL model which does not account for this factor (Model 1): Likelihood ratio=46.43, $\chi_{2}^{2}(.01)=9.22$. This confirms that even when transactions costs are fully discounted there is still a significant difference between markets with positive FLB and those where FLB is absent. This invites the conclusion that transactions costs do not account for differences in FLB in the markets examined.

Table 3: Results of estimating two CL models with index functions made up of an interaction term between Lodds and the transaction costs in a given game $\left(c_{j}\right)$ and, in Model 1, Lodds, and in Model 2, interaction terms between Lodds and binary variables which account for whether a particular market is weak form efficient $\left(e_{1}\right)$ or displays positive $\operatorname{FLB}\left(e_{2}\right)$.

\begin{tabular}{|c|c|c|}
\hline Predictor & Coefficient & $z$-value \\
\hline $\begin{array}{l}\text { Model } 1 \\
\mathrm{c}_{j} \text { Lodds } \\
\text { Lodds } \\
\text { Log- } \\
\text { likelihood }\end{array}$ & $\begin{array}{l}1.0125 \\
0.0116 \\
-53392.6\end{array}$ & $\begin{array}{l}1.39 \\
0.01\end{array}$ \\
\hline $\begin{array}{l}\text { Model } 2 \\
\mathrm{c}_{j} \text { Lodds } \\
e_{1} \text { Lodds } \\
e_{2} \text { Lodds } \\
\text { Log- } \\
\text { likelihood }\end{array}$ & $\begin{array}{l}0.7978 \\
0.1358 \\
0.3142 \\
-53369.4\end{array}$ & $\begin{array}{l}1.08 \\
0.17 \\
0.38\end{array}$ \\
\hline
\end{tabular}

* Significant at 5\% 
The results of Procedures 4 and 5 are presented in Table 4. Correlations between the degree of FLB and, respectively, the mean AGD and the McFadden $R^{2}$ statistics are $0.627(t=3.60)$ and $0.842(t=6.98)$, confirm that competitiveness is a highly significant factor in explaining crossleague efficiency differences.

Table 4: Results of estimating coefficients of interaction terms between Lodds and binary variables indicating the league in which the particular game is played, in CL functions, estimated employing the 52,865 soccer games, 1999-2008 (the coefficients identify the degree of FLB in each league), together with associated McFadden $\mathrm{R}^{2}$ values and mean absolute goal difference for the respective leagues.

\begin{tabular}{lccc}
\hline League & $\begin{array}{c}\text { Coefficient } \\
\text { identifying } \\
\text { degree of } \\
\text { FLB }\end{array}$ & McFadden R & $\begin{array}{c}\text { Mean absolute goal } \\
\text { difference }\end{array}$ \\
\hline Spain2 & 0.936 & 0.0305 & \\
England3 & 0.989 & 0.0417 & 0.2034 \\
Scotland1 & 0.999 & 0.0522 & 0.2740 \\
England1 & 1.019 & 0.0475 & 0.3540 \\
England2 & 1.029 & 0.0474 & 0.2722 \\
Spain1 & 1.044 & 0.0767 & 0.2816 \\
Scotland2 & 1.090 & 0.0571 & 0.3074 \\
Germany2 & 1.103 & 0.065 & 0.3357 \\
Germany1 & 1.117 & 0.0886 & 0.3204 \\
England Conf. & 1.125 & 0.0557 & 0.3457 \\
France1 & 1.128 & 0.0653 & 0.2325 \\
Portugal1 & 1.136 & 0.1040 & 0.2642 \\
Turkey1 & 1.170 & 0.1198 & 0.3564 \\
England Prem. & 1.191 & 0.1136 & 0.3935 \\
Scotland Prem. & 1.194 & 0.1500 & 0.3704 \\
France2 & 1.204 & 0.0621 & 0.4722 \\
Belgium1 & 1.208 & 0.1193 & 0.2387 \\
Netherlands1 & 1.247 & 0.1430 & 0.4887 \\
Italy1 & 1.253 & 0.1276 & 0.4837 \\
Italy2 & 1.27 & 0.0927 & 0.3732 \\
Scotland3 & 1.314 & 0.1226 & 0.2612 \\
Greece1 & 1.344 & 0.1873 & 0.5770 \\
\hline
\end{tabular}

\subsection{Conclusion}

This study analyses a financial market unfettered by factors held to inhibit efficient market outcomes in other contexts. It demonstrates that, even under such favourable conditions, inefficiency can be significant. Whilst transactions costs are ruled out as a direct cause of the inefficiency, an influential factor is a difficulty in assessing the probabilities associated with alternative outcomes of events which determine the traded assets' values. This suggests that markets may invariably be susceptible to fundamental risk evaluation problems. Consequently, in supporting markets to operate with tolerable levels of inefficiency, it is important to avoid institutional features or encouraging behaviours which add further stress to the appropriate valuation of assets and thereby the market's viability. To this end, prohibiting the development 
of exotic derivative assets and discouraging bubbles of positive sentiment may contribute to sustainable, if not wholly efficient, markets.

\section{References}

Acharya V V and Richardson MP (2009) Causes of the Financial Crisis, Critical Review, 21, 195210.

Smith M D and Brynjolfsson E (2000) Frictionless commerce? A comparison of internet and conventional retailers, Management Science, 46, 563-585.

Vaughan Williams L and Paton D (1997) Why is there a favourite-longshot bias in British racetrack betting markets? Economic Journal, 107, 150-158.

Volcker, P. (2011). Financial reform: Unfinished business. The New York Review of Books, 58(18), 1-6. 